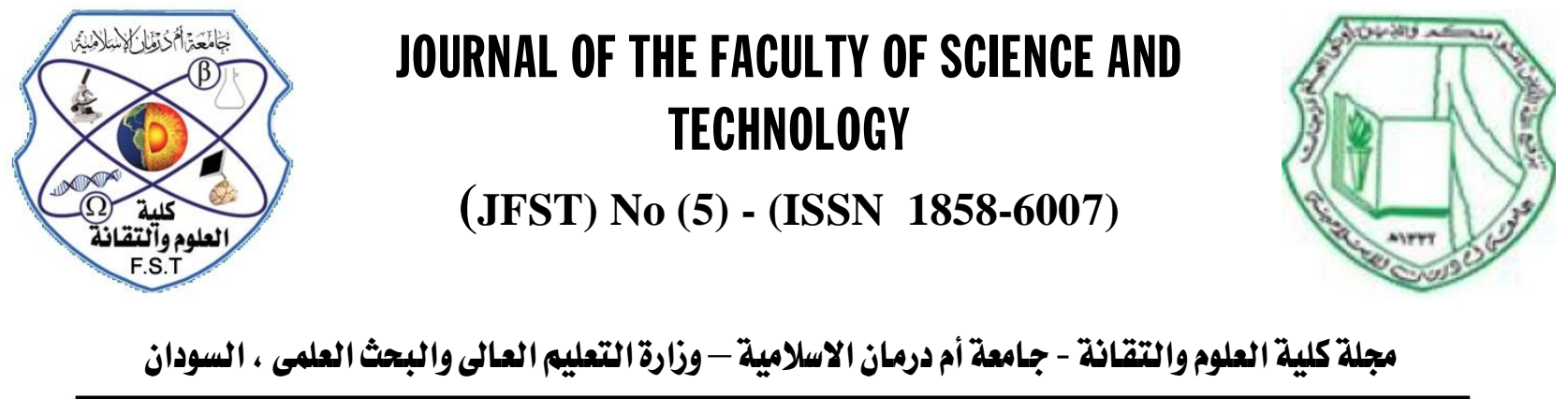

Research Article

\title{
Establishing infection with Echinococcus granulosus hydatid cyst From Bovine origin in dogs
}

\author{
Nadia,A.Ali* .,M.Magzob**, and Elmalik, Khitma,H. ***
}

\begin{abstract}
Establishing infection with Echinococcus granulosus had often created a challenge where by the actual role of the different Intermediate hosts could not be precisely determined. This study was consequently planned to examine the efficiency of cattle as intermediate hosts in the transmission of E. granulosus to canine final hosts. A modified procedure was followed where dogs were fed whole viable hydatid cysts as compared to viable protoscoleces obtained from hydatid sand mixed with meat. Successful transmission was attained as indicated by the presence of ova at faecal examination and adult worm recovery at post - mortem examination. The pre-patent period ranged between $30-42$ days. It was apparent that the non capsulated protoscoleces were defected to the extend that they could not develop to maturity in the dog's viscera. This modification needs to be applied to verify the efficiency of different intermediate hosts in the transmission cycle of Echinococcosis.
\end{abstract}

Key words

Bovine; Hydatid cyst; Echinococcus granulosu; Dog; Health zoonosis.

\footnotetext{
*Nadia,A.Ali. Department of zoology, Faculty of Science and Technology Omdurman Islamic University. E.mail:.Umannas@gmail.com.

**M.Magzob professor.Parasitology department. Faculty of veterinary medicine.University of Khartoum.profmagzoub@gmail.com

*** Kitma H.Malik. professor. Preventive medicine department. Faculty of veterinary medicine. University of Khartoum. E- mail:Ketmalik@ hotmail.com
} 


\section{INTRODUCTION}

Cystic Echinococcosis (CE), caused by the larval stages of the tapeworm Echinococcus granulosus, is known to be one of the most important parasitic infections in livestock worldwide and one of the most wide spread parasitic zoonoses (Craig et al, 2007; Cringoli et al, 2007).

The life cycle of E. granulosus involves domestic and wild animals as definitive hosts, which are infected by the ingestion of offal containing the larval forms, (hydatid cysts), with viable protoscoleces, producing adult stages in the small intestines. Dogs are the main source of infection,

although in some areas jackals, hyenas, foxes, and wolves could also play a role as definitive hosts. The intermediate hosts are a wide range of domestic

and wild mammals and humans, in which the larval stages develop after oral ingestion of eggs (Seimenis, 2003).

Hydatidosis is a significant economic and public health problem in Sudan as described by, Eisa et al, (1977); Magzoub and Saad, (1986), Elhussien and Ali (1990), \& Mohamed (2000). They all reported the disease in both definitive and intermediate hosts in different parts of the country.

The disease is not clinically manifest although it is a chronic condition where fluid-filled cysts are formed in any part of the body. Domestic intermediate hosts (cattle, sheep, goats, and camels) are major reservoir hosts for human Cystic Echinococcosis caused by Echinococcus granulosus in the East African region (Macpherson et al, 1989).

The Pre-patent period was shown by Thompson et al, (2001) to be 6-8 weeks after infection depending on the species, strain, and the susceptibility of the host. Experimental transmission of Echinococcus granulosus infection to dogs in Sudan was done by Slepnev et al, (1977) who reported 46-50, days for pre-patent period, Idris ,(1985) reported 45- 53 days, while Saad, (1985) and Mohamed \& Elmalik, (2000) reported 37-63 days.

Epidemiological and molecular studies were conducted to investigate the role of cattle in the transmission of cystic echinococcosis (CE) in Southern Italy, $10.4 \%$ of the examined cattle were found infected. The cysts were either sterile $(42.7 \%)$ calcified or caseous (57.3\%); no fertile cysts were found. The findings reported in these studies showed that $\mathrm{CE}$ is widespread between cattle bred in the Southern Italy. However, the absence of fertile cysts suggests that cattle would not have any role in the persistence of this important zoonosis but rather have a role as indicators of $\mathrm{CE}$ infection in this endemic area. (Rinaldi, et al., 2008). 
Macpherson, et al., (1985), could not establish the infection from cattle to dogs in his research carried in Kenya.

Most of the successful experimental transmission of Echinococcus granulosus infection to dogs in Sudan was done from camels to dogs.

No successful transmission of hydatid cyst from cattle to dogs was established in the Sudan except what was reported by Saad, (1985) who did not mention detailed procedure for transmission.

The objective of this study is to develop a procedure for establishing infection from bovine origin by adapting the natural infection where dogs ingest whole cysts.

\section{MATERIALS AND METHODS}

\section{1-Experimental animals}

20 puppies of mixed breeds approximately 3-6 months of age were obtained. Faecal samples of each were examined three times to confirm their freedom from eggs of any taeniidea worms. The dogs were kept in cages in the laboratory of the department of Parasitology and were divided into 4 groups, (1A,2A,1B and 2B ).

\section{2- Hydatid cysts}

Viable hydatid cysts from livers, and lungs of naturally infected cattle slaughtered at AL Arabawii, Sabaloga, or Ganawa Abattoirs of Khartoum state were collected. The viability of the protoscoleces was determined by observing flame cell activity (Calero, et al., 1978).

Viable protoscoleces used for experimental infection were counted. Dogs were starved 8-12 hours before they were infected.

\section{3- Experimental design}

Two sets of Experiments were performing.

\section{Experiment (A)}

Puppies in groups $1 \mathrm{~A}$ and $2 \mathrm{~A}$ were included, each composed of 5 puppies.

Each dog in group 1A was dosed with protoscoleces from cattle lungs in offal meat harboring approximately 6,000 protoscoleces, while each dog in group 2A received the same number of protoscoleces from cattle livers origin. All the puppies were kept under similar feeding and management conditions throughout the course of study.

\section{Experiment (B)}

Puppies in groups 1B and 2B 5puppies each were included. These were infected, but with the whole cysts after being examined for viable protoscoleces. Group 1B puppies were given hydatid cysts from the lungs of infected cattle and the 2B were given hydatid cysts from the livers of infected cattle.

\section{Follow up}

All animals were observed up to 60 days. The procedure for infection detection started 3 weeks post infection. 
Faecal samples from each dog were examined twice weekly for eggs of Echinococcus spp till necropsy.

Puppies were euthanized at intervals between 35-60 days after the experimental infection by intravenous injection of $100 \mathrm{mg}$ Thiopentalsod. All animals were starved for 18 hours before being autopsied. The adult worms were collected by incising the small intestines of puppies, the mucosal surface scraped with spatula to free the attached worms. The contents were diluted with normal saline and a small amount was placed in petry dishes.

The dishes were placing against black back ground, and by the help of magnifying hand lens. Worms encountered were collected by Pasteur pipette. The procedure was repeated many times for the whole contents. The worms if present were identified, counted, evaluated for sexual maturity, examined and photographed under the microscope and preserved in Rouda bush and in $70 \%$ ethanol for further identification.

\section{RESULTS}

All infected puppies in group 1A and $2 \mathrm{~A}$ gave negative faecal samples results for eggs of Echinococcus granulosus during the whole period of the experiment. No eggs appeared in the faeces. Likewise no worms were recovered in the small intestines of dogs autopsied at different intervals post infection.

As for groups 1B and 2B Echinococcus granulosus worms were established in all dogs which were infected with the intact hydatid cyst carrying viable protoscoleces as shown in table 1. Faecal samples results for eggs of Echinococcus granulosus were positive after 4 weeks of infection. The prepatent period ranged between 30 and 41 days post infection. 
Table 1: Patency in dogs experimentally infected with Echinococcus granulosus from naturally infected cattle

\begin{tabular}{|l|l|l|l|l|}
\hline $\begin{array}{l}\text { Experiments } \\
\text { No. }\end{array}$ & $\begin{array}{l}\text { Organ of cysts } \\
\text { collection }\end{array}$ & $\begin{array}{l}\text { No. of protosclices } \\
\text { Administered }\end{array}$ & $\begin{array}{l}\text { P.P } \\
(\text { dpi) } \\
\text { (ova detection) }\end{array}$ & $\begin{array}{l}\text { P.M. (dpi) (adult worms } \\
\text { detection) }\end{array}$ \\
\hline$(1 \mathrm{~A})$ & Lungs & 6000 & No ova & $35-60$ (No worms seen) \\
\hline$(2 \mathrm{~A})$ & Liver & 6000 & No ova & $35-60$ (No worms seen) \\
\hline$(1 \mathrm{~B})$ & Lungs & $\begin{array}{l}\text { Whole cysts viable } \\
\text { protosclices }\end{array}$ & $30-41$ & $30-60$ \\
\hline$(2 \mathrm{~B})$ & Liver & $\begin{array}{l}\text { Whole cysts viable } \\
\text { protosclices }\end{array}$ & $31-42$ & $30-60$ \\
\hline
\end{tabular}

p.p $=$ the pre-patent period

P.M. = Post mortem - (between 35-60 days)

d.p.i $=$ days post infection

\section{DISCUSSION}

The information presented represented successful experimental transmission of Echinococcus granulosus of cattle origin to dogs in Sudan using a modified procedure. The comparison of infectivity of capsulated cysts to encapsulated viable protoscoleces was tried to verify the observation that natural infection in final hosts is due to ingestion of whole capsulated cysts. Literature search revealed limited information on transmission of Echinococcus granulosus from cattle to dogs. They were considered as indicators (Rinaldi, et al.,2008), as well reports of high incidence of sterile or calcified cysts lead to the inclination that cattle could not be efficient intermediate hosts.

The only report from Sudan (Saad, 1985) stated transmission from cattle to dogs, but it was not possible to repeat this transmission by subsequent workers (Mohamed, 1996; Mohamed, 2004).

After pre - patent period of 30- 40 days dogs infected with whole cysts were tested positive. It seems that the detrimental effect of peptic enzymes affected negatively the development of worms to maturity. Comparative results were observed for Raillietina tetragon where the cysticercoids had to be protected in gelatin capsules before infection. It 
could be possible that protoscoleces of cattle origin are more sensitive to digestive enzymes than those from camel origin.

This result raises concern, especially in rural setups, where proper disposal of offal's and discarded tissues from slaughtered animals is not observed. Hydatid cysts may thus be available for dogs so a transmission cycle is complete. This does not only affect animals but a human health hazard is created as this parasite is a known zoonotic worm. It was noticeable that the risk of getting infected is high in pastoral communities, with poor hygiene, and where dogs are used to herd animals (Andersen, 1997).

\section{References}

Andersen, F. L., H. Ouhelli, and M. Kachani. 1997. Compendium on cystic echinococcosis in Africa and in Middle Eastern Countries with Special Reference to Morocco. Brigham Young University Print Services, Provo, Calero, R., Anguiano, A., Acosta, I., Domingues, M. and Hernandez, S., 1978. Variation of different components of hydatid liquid, in relation to the organic localization, fertility and viability of the cysts. Short Communications Organizing Committee, Section C. Warsa, Poland, pp. 128-129. Helminthol., 48: 5501
Craig PS, McManus DP, Lightowlers MW, Chabalgoity JA, Garcia HH, Gavidia CM, Gilman RH, Gonzalez AE, Lorca M, Naquira C, Nieto A, Schantz PM (2007) Prevention and control of Cystic Echinococcosis. Lancet Infect Dis 7:385394.

Cringoli G, Rinaldi L, Musella V, Veneziano V, Maurelli MP, Di Pietro F, Frisiello M, Di Pietro S (2007). Live stock farms as tools for the epidemiology of studying cystic echinococcosis in cattle and water buffaloes from southern Italy. Geospatial Health 2:105-111.

Eisa, A. M.; El Kawad,S.E.and Slepnev,N. K. (1977). Survey of Parasites of dogs in Khartoum Province. Proceeding of the $8^{\text {th }}$ veterinary Conference (Livestock and animal production in the Sudan, 22-26 hydatidosis April, 64-67.

Eisa, A.M., Mustafa, A.A. and Soliman, K.N. (1962) Preliminary report on cysticercosis and hydatidosis in Southern Sudan.Sudan Journal of Veterinary Science 3:97-108.

Elhussien, A.M. and Ali, S.M. (1990), A note on hydatidosis in camels at El Damer province, Northern

State,Sudan.Sud.J.Vet.Res. 10: 6364

Idris, y. A. (1985). Some aspects of epidemiology of echinococcosis/ Hydatidosis in the Sudan. M. V. Sc. Thesis. University of Khartoum Magzoub and Saad, (1986), Echinococcus granulosus 
infection in Tampool,

Sudan.J.Helminthol.60:299 - 300

Macpherson, C. N. L., Spoerry A., Zeyhle

E., Romig T., and Gorfe M., (1989) -

Pastoralists and hydatid disease: an

ultrasound scanning prevalence survey in

East Africa.Trans,roy Soc.trop.Med.Hyg., 83, $243-247$.

Macpherson C.N., French C.M., Stevenson

P., Karstad L. and Arundel J.H. (1985).

Hydatid disease in the Turkana District of

Kenya, IV. The prevalence of Echinococcus

granulosus infections in dogs, and

observations on the role of the dog in the

lifestyle of the Turkana. Annals of Tropical

Medicine and Parasitology 79: 51-61.

Mohamed and Elmalik, (2000) The

Epidemiology of Cystic Echinococcosis in

Nyala, Southern Darfur State,Sudan. Sud.

J.Vet. Res. 49 -53.

Rinaldi, L. \& M. P. Maurelli \& V. Veneziano \& F. Capuano \&A. G. Perugini $\&$ S. Cringoli (2008) The role of cattle in the epidemiology of Echinococcus granulosus in an endemic area of southern Italy. Parasitol Res 103:175-179.

Saad, M. B., (1985) Experimental transmission of hydatid infection from camls and cattle to dogs. Annals of Tropical Medicine and Parasitology, 82:363 - 365.

Seimenis A (2003) Overview of the epidemiological situation on echinococcosis in the Mediterranean region. Acta Trop 85:191-195.

Slepnev,N. K.,Eisa,A.M.\&Saad,M.B. (1977) Prepatent period of Echinococcus granulosus in dogin Sudan. Journal of Veterinary Science and AnimalHusbandry, 17:12 - 15.

Thompson, R. C. A., and D. P. McManus. 2001. Aetiology: parasites and life-cyles, p. 1-19. In J. Eckert, M. A. Gemmell, F.-X. Meslin, and Z. S. Pawlowski (ed.), WHO/OIE manual on echinococcosis in humans and animals: a public health problem of global concern. World Organisation for Animal Health, Paris, France. 